\title{
Alcohol consumption and sleep deprivation among Ghanaian adults: Ghana demographic and Health Survey
}

\author{
Sanni Yaya ${ }^{1}$, Ruoxi Wang ${ }^{2}$, Shangfeng Tang ${ }^{2}$, Bishwajit Ghose ${ }^{\text {Corresp. } 1}$ \\ ${ }^{1}$ School of International Development and Global Studies, University of Ottawa, Ottawa, Ontario, Canada \\ ${ }^{2}$ School of Medicine and Health Management, Huazhong University of Science and Technology, Wuhan, China \\ Corresponding Author: Bishwajit Ghose \\ Email address: brammaputram@gmail.com
}

Abstract Heavy consumption of alcohol has shown to be associated with sleep disturbances among adult and elderly people in high income settings. So far, the relationship between alcohol drinking and sleeping pattern has not been studied in an African setting. Therefore, in this study we investigated whether alcohol consumption has any influence on sleeping hours among adult men and women in Ghana. Methods Data for this survey were extracted from Ghana Demographic and Health Survey (GDHS 2008). GDHS is the only cross-sectional survey conducted on men and women aged above 15 years that collected information on variables such as sleeping hours and alcohol consumption. The analysis was controlled for various demographic, socioeconomic, household level factors and smoking. Results Prevalence of sleeping 1-3h, 4-6h, and $>7 \mathrm{~h}$ was respectively $1.5 \%(1.2-2.0), 14.1 \%(12-16.5)$ and $84.4 \%$ (82.1-86.4), and that of alcohol use was $26.9 \%$ (23.4-30.6). In the multivariable regression analysis, compared with non-drinkers, those reported drinking had significantly lower odds of sleeping for at least seven hours. In the adjusted model, drinkers had 0.8 times (Adjusted $\mathrm{OR}=0.803$, $95 \% \mathrm{Cl}=0.690-0.935)$ lower odds of sleeping for at least seven hours. The odds for sleeping 4-6 hours were not statistically significant. In the stratified analysis, the odds of sleeping for at least seven were comparatively lower among women (Adjusted $\mathrm{OR}=0.657$, $95 \% \mathrm{Cl}=0.509-0.849$ ) then among men (Adjusted $\mathrm{OR}=0.867,95 \% \mathrm{Cl}=0.740-0.965$ ).

Conclusion Men and women who reported consuming alcohol had significantly lower odds of getting adequate sleep ( $>7$ hours). The sleep-disrupting effect of alcohol appeared to be more prominent among women than among men. Currently there is not sufficient evidence on alcohol consumption and sleep disorder among Ghanaian population or any other country in the region. Further studies are required to understand sleeping patterns and the burden of alcohol drinking in this population to design intervention programs. 
1 Alcohol consumption and sleep deprivation among Ghanaian adults: Ghana demographic and

2

3

4

5

61 School of International Development and Global Studies, University of Ottawa, Ottawa, 7 Canada

82 School of Medicine and Health Management, Tongji Medical College, Wuhan, China

11 Emails:

12 Sanni Yaya: sanni.yaya@uOttawa.ca

13 Ruoxi Wang: ruoxiwang@,hust.edu.cn

14 Shangfeng Tang: sftang@,hust.edu.cn

15 Ghose Bishwajit: brammaputram@gmail.com (correspondence) 
27 Abstract Heavy consumption of alcohol has shown to be associated with sleep disturbances among adult and elderly people in high income settings. So far, the relationship between alcohol drinking and sleeping pattern has not been studied in an African setting. Therefore, in this study we investigated whether alcohol consumption has any influence on sleeping hours among adult men and women in Ghana.

Methods Data for this survey were extracted from Ghana Demographic and Health Survey (GDHS 2008). GDHS is the only cross-sectional survey conducted on men and women aged above 15 years that collected information on variables such as sleeping hours and alcohol consumption. The analysis was controlled for various demographic, socioeconomic, household level factors and smoking.

Results Prevalence of sleeping 1-3h, 4-6h, and $\geq 7 \mathrm{~h}$ was respectively $1.5 \%(1.2-2.0), 14.1 \%$ (12$16.5)$ and $84.4 \%(82.1-86.4)$, and that of alcohol use was $26.9 \%$ (23.4-30.6). In the multivariable regression analysis, compared with non-drinkers, those reported drinking had significantly lower odds of sleeping for at least seven hours. In the adjusted model, drinkers had 0.8 times (Adjusted $\mathrm{OR}=0.803,95 \% \mathrm{CI}=0.690-0.935)$ lower odds of sleeping for at least seven hours. The odds for sleeping 4-6 hours were not statistically significant. In the stratified analysis, the odds of sleeping for at least seven were comparatively lower among women (Adjusted $\mathrm{OR}=0.657,95 \% \mathrm{CI}=0.509$ 0.849 ) then among men (Adjusted $\mathrm{OR}=0.867,95 \% \mathrm{CI}=0.740-0.965$ ).

Conclusion Men and women who reported consuming alcohol had significantly lower odds of getting adequate sleep ( $\geq 7$ hours). The sleep-disrupting effect of alcohol appeared to be more prominent among women than among men. Currently there is not sufficient evidence on alcohol consumption and sleep disorder among Ghanaian population or any other country in the region. Further studies are required to understand sleeping patterns and the burden of alcohol drinking in this population to design intervention programs. 


\section{Introduction}

Alcohol consumption accounts for approximately 4\% of all-cause global mortality and 5\% of the global disease burden(Beaglehole \& Bonita, 2009). As such, alcohol is recognised by healthcare systems as a major risk factor for a host of physical and psychological illnesses, injuries and selfharm, as well as social issues that create significant bearing on indicators such as potential years of life lost (PYLL), and disability-adjusted life years (DALYs)(Tai Hing Lam \& Chim, 2010)(Collin, Hill \& Smith, 2015)(Rabiee et al.)(Shield et al., 2012). Advances in molecular pathology has greatly facilitated the understanding of the underlying mechanisms through which alcohol affects major regulatory systems leading to endocrine disorder and associated consequences such as disruption of the circadian rhythm (Process C) (1997; De Coster \& van Larebeke, 2012; Rachdaoui \& Sarkar, 2013, 2017). As an endocrine-disrupting agent, and complex interaction with body's circadian rhythm, alcohol has become a subject of widespread interest among health scientists (“Alcohol' s Interactions With Circadian Rhythms").

One of the key issues concerned with the alcohol-induced disruption of the circadian rhythm (clock-hormone interaction) is altered sleep architecture (e.g. nocturnal sleep disruption, excessive daytime sleepiness)(Jafari Roodbandi, Choobineh \& Daneshvar, 2015) as it plays a key role in the regulation of sleep homeostasis, disruption of which is a primary cause of sleeplessness (Thakkar, Sharma \& Sahota, 2015). General sleep deprivation is a growing health concern and despite that it remains largely ignored in the population health promotion agenda (Moloney, Konrad \& Zimmer, 2011). The cumulative effects of sleep disorders have been shown to trigger a wide-ranging physical and mental health consequences, poor academic and workplace productivity, decreased quality-of-life (QoL) and well-being, and high healthcare expenditures (Soares, 2005; Hillman, Murphy \& Pezzullo, 2006; Johansson et al., 2010; Ishak et al., 2012). For instance, the overall cost of sleep disorders in Australia was dollar estimated to be \$7494 million(Hillman, Murphy \& Pezzullo, 2006), while in the USA, it was estimated that societal costs of alcohol-related sleep disorders exceeds \$18 billion(Thakkar, Sharma \& Sahota, 2015).

The pathophysiology of sleep disorder is multifactorial, and the risk factors vary among people across different cultures, demographics, environment, socioeconomic situation. Apart from that, a growing body of research suggests that the epidemic of sleep disorder is being fuelled by 
85

86

87

changing lifestyle behaviour e.g. dietary habits, drug abuse, alcohol consumption and smoking(Mahfoud et al., 2009; Krishnan, Dixon-Williams \& Thornton, 2014; Pot, 2017). As a result, pharmacological interventions of sleep disorder are becoming increasingly popular, however with multitude of potential disadvantages. In addition, various behavioural intervention techniques are also being tested such as sleep restriction therapy, sleep hygiene, paradoxical intention therapy, cognitive behavioural therapies(Sharma \& Andrade, 2012). Despite these advances, treating alcohol-induced sleep problems remains a challenging one, particularly due to the complexities during withdrawal(Brower, 2001).

Despite the emerging evidences on the adverse impacts of alcohol, the rate of consumption is increasing in LMICs(Martinez et al., 2011; Tian \& Liu, 2011). According to World Health Organization estimates, Sub Saharan Africa (SSA) ranks among the regions with highest per capita consumption of alcohol in the world(WHO., 2013). Data on sleep health, on the other hand, is extremely scarce for Ghana. However, it is assumable that the population is experiencing an increasing prevalence of sleep disorder given the growing popularity of alcoholic beverages. To address the current research gap we undertook this study based on publicly available data from Ghana Demographic and Health Survey (GDHS) conducted in 2008. Although more recent survey data have been published, information on sleeping hours were included only in the 2008 survey. The main objectives of the study were to investigate the prevalence of sleep deprivation, as well its association with alcohol consumption status among men and women.

\section{Methods}

Survey methods

The 2008 GDHS was the fifth to be undertaken in the country. This was a country-wide survey that covered all ten regions in the country. The main components of DHS include maternal and child health indicators such as fertility, family planning, breastfeeding, nutritional status of women and young children, childhood mortality. The survey was carried out by the Ghana Statistical Service (GSS) and the Ghana Health Service (GHS) with technical support from MEASURE DHS programme and financial assistance from the United States Agency for 
114 International Development (USAID). The survey employed a two-stage sampling design to 115 ensure representativeness of the population. The first stage involved selecting clusters (in total 116412 were selected) from a master sampling frame constructed from the 2000 Ghana Population 117 and Housing Census. In the second stage, a systematic selection of households (30 households 118 from each cluster) was conducted from each cluster. A total of 5,096 women and 4,769 men 119 were identified as eligible for survey, of who interviews were completed with 4,916 women 120 (response rate of 97\%) and 4,568 men (response rate of 96\%). Field work for the survey lasted 121 from 8 September to 25 November 2008. Further details about the survey are available at: Ghana 122 Statistical Service (GSS), Ghana Health Service (GHS), and ICF Macro. 2009. Ghana 123 Demographic and Health Survey 2008. Accra, Ghana: GSS, GHS, and ICF Macro.

124 Variable used in the study

125 Outcome variable was self-reported hours of sleeping. This was assessed by asking the 126 participants: How many hours do you rest a day, including naps and sleep both during day and 127 night? Responses were collected in the following categories: 1-3 hours, 4-6 hours, 7-9 hours, 10 128 and don't know. For the purpose of this study the categories were merged followingly: 1-3 hours, 129 4-6 hours, 6+ hours. This was guided by the recommendations by WHO on sleep hours which 130 maintains that adults should sleep 7 or more hours per night on a regular basis to promote 131 optimal health(Watson et al., 2015). Sleeping less than 7 hours per night has been shown to be 132 associated with various health consequences including obesity, impaired immune function, 133 diabetes, hypertension, heart disease and stroke, depression, and increased mortality rates 134 (Watson et al., 2015).

135

136

137

138

139

140

141

142

Main explanatory variable was alcohol drinking. Participants were asked whether or not they drink alcoholic beverages. As the information on the exact volume of consumption was not available, the answers were categorized as: Drinker if responded as yes, and Non-drinker if no.

To measure the independent association between alcohol drinking and sleeping hours, the analysis was adjusted for a range of potentially confounding variables such demographic, household, and socioeconomic status. For the purpose of selecting confounding variables that were available on the dataset, we conducted a literature review to identify which ones are theoretically related with alcohol drinking and sleep disturbance. Based on the review the 
143 following variables were finally selected for the analysis- Age: 15-19/20-24/ 25-29/ 30-34/ 35-

144 39/ 40-44/ 44+; Sex: Male/ Female; Residency: urban/ rural; Religion: Christian/ Non145 Christian; Ethnicity: Akan/ Ewe/ Mole-Dagbani/ Other; Education: No education/ primary/ 146 Secondary/ Higher; No. of household member: 4/ 6/ 8/ 8+; Has electricity: No/ Yes; No. of 147 rooms for sleeping: 2/ 4/ 6/ 6+; Has Bed: No/ Yes; Has bed net: No/ Yes; Wealth index: 148 Poorest /Poorer/ Middle/ Richer/ Richest; Working: No/ Yes; Smokes cigar: No/ Yes.

Data analysis

151

152

153

154

155

156

157

158

159

160

161

162

163

164

165

166

167

168

169

170

171

Data analyses were performed with SPSS version 24 for windows. The datasets (men's and women's dataset) were checked for outliers, multicollinearity among variables, and then merged to perform pooled analysis. As the survey used multistage sampling techniques, regular analytical procedures were not suitable as they cannot adjust for cluster effects. In order to adjust for this effect, the dataset was prepared for complex analysis accounting for the primary sampling units, sample strata and weight. This allowed complex sample analysis which is recommended for DHS data. After preparing the file, descriptive analyses were carried out to calculate the basic sociodemographic characteristics of the sample population and the prevalence of sleeping hours. These results were presented as percentages with 95\% CIs. Following that, Chi-square bivariate tests were performed to calculate the prevalence of sleeping hours across the explanatory variables and the significance of these associations. Variables significant at $\mathrm{p}<0.25$ were entered into the multivariate model. We used multinomial logistic regression analyses to calculate the adjusted odds ratios of the association between the alcohol consumption and sleeping hours while controlling for the potentially confounding variables. Four different models were formed to see the contribution of the variables at certain types on the odds ratios. The level of significance was set at $\mathrm{p}<0.05$ for regression analyses.

\section{Ethics statement}

DHS surveys are approved by ICF (Inner city fund) international, USA. All participants gave informed consent before taking part in the survey. Data are available in the public domain in anonymised form, therefore no additional approval was necessary. 


\section{Results}

174 Descriptive statistics

175 Basic sociodemographic profile of the participants was presented in Table-1. In total 4546 men 176 and 4907 women were included in the analysis. Mean age of the participants were 28.99 years 177 (SD 9.7), 31.67 years (SD 12.24) among men and 28.99 (SD 9.70) among women.

178 Most of the participants were in the age groups of 15-19 years, were female, rural residents, 179 followers of Christianity, of Akan ethnicity, had secondary level education. Most of the 180 households had 4 members, had access to electricity, had 2 living rooms, possessed bed, bed net, 181 from richer to richest households. Majority of the participants had employment, were non182 smoker and non-drinker.

Sleeping hours

188

189

190

191

192

193

194

195

196

197

More than four-fifth of the participants $(84.4 \%, 95 \% \mathrm{CI}=82.1-86.4)$ reported sleeping for more than 7 hours on an average day. Prevalence of sleeping 1-3h, 4-6h, and $\geq 7 \mathrm{~h}$ was respectively $1.5 \%(95 \% \mathrm{CI}=1.2-2.0)$ and $14.1 \%(95 \% \mathrm{CI}=12-16.5)$. From Table- 2 it appears that the prevalence of sleeping $\geq 7$ hours were comparatively higher among those aged below 30 years, female, rural residents, non-Christian, of Akan ethnicity, had secondary level education, lived in households composed of four members, had access to electricity, had two rooms for sleeping, possessed bed and bed net, non-poor households (richest/richer), had employment, were non-smoker and nondrinker. 
Association between alcohol drinking and adequacy of sleeping hours

201

202

203

204

205

206

207

208

209

210

211

212

213

214

215

216

217

218

219

220

221

222

223

224

225

Results of multivariable regression analysis on the association between alcohol drinking of any frequency and sleeping hours were presented in Table-3. In the pooled analysis, compared with non-drinking participants, those who drink had significantly lower odds of sleeping for at least 7 hours. For example, in the fully adjusted model drinkers had 0.8 times ( $\mathrm{AOR}=0.803$, $95 \% \mathrm{CI}=0.690-0.935)$ lower odds of sleeping for at least seven hours and 1.15 times $(\mathrm{AOR}=1.154$, $95 \% \mathrm{CI}=0.713-1.868$ ) higher odds of sleeping for 4-6 hours. However, the odds for sleeping 4-6 hours were not statistically significant. In the stratified analysis, the strength of the association appeared to be higher among women compared with men. After adjusting for all the potential confounders, the odds of at least $7 \mathrm{~h}$ of sleeping was 0.65 times $(\mathrm{AOR}=0.657,95 \% \mathrm{CI}=0.509$ $0.849)$ lower compared with odds ratios of $0.86(\mathrm{AOR}=0.867,95 \% \mathrm{CI}=0.740-0.965)$ among men.

\section{Table 3: Odds ratios of sleeping 4-6 hours and 1-3 hours among drinkers. GDHS 2008.}

\section{Discussion}

\section{Main findings}

In the present study we found more than a quarter of the participants reported ever drinking alcohol. Regarding sleep disturbance, more than one in ten reported sleeping for less than seven hours, and a smaller fraction (1.5\%) less than six hours a day. Significant sociodemographic patterns were observed in the prevalence of adequate sleeping. Adolescents (15-19 years) had the highest rate of reporting adequate sleeping, followed by those in the age groups of 20-24 and 2429 years. This percentage decreased until the age group of 45-49 years. Women had higher 
226 prevalence of sleeping more than seven and less than four hours, while men had higher

227 prevalence of sleeping four to six hours. Geographic and ethnic differences were also prominent,

228 rural residents had higher prevalence of sleeping for at least seven hours than urban residents.

229 We also found significant association with socioeconomic factors such as education and working

230 status, participants who had secondary level education had employment had higher percentages

231 of sleeping for more than seven hours. Regarding household characteristics, living in households

232 composed of less than five members, had access to electricity, had two rooms for sleeping,

233 possessed bed, of higher wealth status, appeared to have positive association with adequate

234 sleeping hours.

235 Our findings also indicated a positive association between alcohol intake and poor-quality sleep 236 measured in terms of sleeping hours. Data on sleeping hours were collected as brackets (e.g. 1-

$2373 \mathrm{~h}$ ), and not as continuous measures, which prevented us from conducting a linear regression 238 analysis which could have provided a more robust picture of the association between alcohol 239 intake and sleep disturbance. One interesting aspect regarding the association is that alcohol use 240 decreased the odds of sleeping for $\geq 7$ only, not for 4-6h. Of note, these variations persisted for all 241 levels of adjustment (partial and full) as adding the variables in groups by types did not make 242 any noticeable different in the effect size. Further studies will be required to explore the 243 mechanisms of these variations.

Previous findings and research directions

246 Epidemiological studies on nationally representative sample in the areas of sleep medicine is rare 247 for sub-Saharan countries. In recent years the number of studies on sleep health on sub-national 248 population has increased in Nigeria and South Africa, however the studies vary in 249 methodological approaches for measuring sleep quality and sleeping hours. Therefore, the 250 findings on the prevalence of adequate sleeping hours are hard to compare with previous 251 researches. One Nigerian study conducted on school-going adolescents in Kano state reported 252 that both the quality and quantity of sleep were suboptimal, and recommended more research 253 attention on the topic(Peter et al., 2017). Similar findings was reported among on school-going 254 adolescents in Ibadan(Balogun, Alohan \& Orimadegun, 2017). Another study on university 255 students found that that mean duration of night sleep was $6.2 \mathrm{~h}$ (Oluwole, 2010). Regarding the 
256 association between alcohol intake and sleep disturbance, the findings of our study are

257 comparable with those from several review(al; Roehrs \& Roth, 2001) and original studies(Stein

258 \& Friedmann, 2005; Singleton \& Wolfson, 2009; Dangour et al., 2013; Kenney et al., 2014; van

259 Schrojenstein Lantman et al., 2017). These studies are based on sample mostly from Asian and

260 European population and involve social drinking instead of problem drinking. Synthesis of

261 current literature reveals that problem alcohol drinking/alcohol abuse is more commonly

262 associated with sleep disturbance compared with social drinking(Brower, 2001; Arnedt, Conroy

263 \& Brower, 2007; Popovici \& French, 2013). Therefore, future studies investigating sleep quality/

264 disorder in association with alcohol use should take into consideration the frequency and degree

265 of drinking.

266

267 General discussion

268 Worldwide, sleep deprivation is a growing public health concern among the scientific 269 community owing to the long-terms consequences on health and quality of life at individual level, 270 and economic costs in terms of productivity loss at national level. Although most of the findings 271 originate from researches in high-income settings, the epidemic is not unique to the wealthy 272 countries as poverty of sleep is being recognised to be a widespread issue in LMICs as well(Shah, 273 Bang \& Bhagat, 2010; Kang et al., 2012; Stranges et al., 2012). In Africa, on the other hand, the 274 issue has remained underemphasised to date and is potentially contributing to the worsening 275 health outcomes and unmet health need of the population. Therefore, it is recommended that 276 universities and health research institutions conduct surveys on sleep health especially in the 277 context of alcohol consumption and inform authorities for taking appropriate policy action(Hahn, 278 Woolf-King \& Muyindike, 2011; O’Connell et al., 2013; Ferreira-Borges, Parry \& Babor, 2017).

280 Strengths and Limitations

281 This is the first study to explore the association between alcohol consumption and adequacy of 282 sleeping hours in an African setting. Some of the strengths include the large sample size and 283 inclusion of both men and women. We were able to control for a large number of potentially 284 confounding variables such as demographic, socioeconomic, and household. Besides the 
285 strengths, there are several important limitations of this study. There was no information on the 286 use of psychoactive medication or any other drug that could influence quality of sleeping. Self287 reported measure of sleeping hours and alcohol intake are subject to recall error and reporting 288 bias. Alcohol intake was categorised as "drinker" and "non-drinker", which prevents making any concrete conclusion such as the minimum frequency and volume of drinking to affect sleeping hours. As the data were cross-sectional, it does not guarantee any causality or directionality of

291

292

293

294

295

296

297

298

299

300

301

302

303

304

305

306

307

308

309

310

311

312 313 the association between the explanatory and outcome variables. It is possible that people who were not able to maintain healthy sleeping habits were more prone to developing drinking behaviour. Another important limitation is that we could not adjust the analysis for factors such as the occurrence of other diseases that are known to affect sleep quality. The survey was conducted in 2008 , therefore the prevalence rates may not represent the current scenario. Future studies should focus on collecting more precise information regarding drinking behaviour among men and women including the elderly population and investigate people's perception of the impact of drinking on subjective sleep quality.

\section{Conclusions}

Our findings indicate that nearly one-fifth of adult men and women in Ghana are not getting adequate sleep. Sleep-deprivation is a multifactorial issue and can arise from various environmental, biological, and lifestyle related behaviours such as alcohol drinking. We also found a significantly positive association between alcohol consumption and inadequate sleeping hours which supports the previous findings that regular use of alcohol may lead to sleep difficulties in the long run. We further observed that the sleep-disrupting effect of alcohol was more prominent among women than among men. Further studies are required to explore the causes of varying sleeping patterns among men and women in relation to alcohol drinking. At health policy making level, programs aimed at reducing alcohol consumption at national level may have positive outcomes on sleep health in the population.

Acknowledgements Authors acknowledge the generous provision of the data that has made the study possible. 


\section{References}

317

al BP et.Alcohol continues to affect sleepiness related driving impairment, when breath alcohol levels have fallen to near-zero. - PubMed - NCBI. Available at https://www.ncbi.nlm.nih.gov/pubmed/15303246 (accessed March 28, 2018).

Alcohol's Interactions With Circadian Rhythms. Available at https://pubs.niaaa.nih.gov/publications/arh25-2/94-100.htm (accessed March 27, 2018).

Arnedt JT., Conroy DA., Brower KJ. 2007. TREATMENT OPTIONS FOR SLEEP DISTURBANCES DURING ALCOHOL RECOVERY. Journal of addictive diseases 26:41-54.

Balogun FM., Alohan AO., Orimadegun AE. 2017. Self-reported sleep pattern, quality, and problems among schooling adolescents in southwestern Nigeria. Sleep Medicine 30:245250. DOI: 10.1016/j.sleep.2016.11.013.

Beaglehole R., Bonita R. 2009. Alcohol: a global health priority. The Lancet 373:2173-2174. DOI: $10.1016 / \mathrm{S} 0140-6736(09) 61168-5$.

Bishwajit G., Tang S., Yaya S., He Z., Feng Z. 2017. Lifestyle Behaviors, Subjective Health, and Quality of Life Among Chinese Men Living With Type 2 Diabetes. American Journal of Men's Health 11:357-364. DOI: 10.1177/1557988316681128.

Brower KJ. 2001. Alcohol's Effects on Sleep in Alcoholics. Alcohol research \& health: the journal of the National Institute on Alcohol Abuse and Alcoholism 25:110-125.

Collin J., Hill SE., Smith KE. 2015. Merging alcohol giants threaten global health. BMJ 351:h6087. DOI: 10.1136/bmj.h6087. 
337 Dangour AD., Watson L., Cumming O., Boisson S., Che Y., Velleman Y., Cavill S., Allen E.,

338 Uauy R. 2013. Interventions to improve water quality and supply, sanitation and hygiene practices, and their effects on the nutritional status of children. The Cochrane Database of Systematic Reviews:CD009382. DOI: 10.1002/14651858.CD009382.pub2.

De Coster S., van Larebeke N. 2012. Endocrine-Disrupting Chemicals: Associated Disorders and Mechanisms of Action. Journal of Environmental and Public Health 2012. DOI: balance. Alcohol Health and Research World 21:53-64.

Hillman DR., Murphy AS., Pezzullo L. 2006. The economic cost of sleep disorders. Sleep

Hahn JA., Woolf-King SE., Muyindike W. 2011. Adding fuel to the fire: alcohol's effect on the HIV epidemic in Sub-Saharan Africa. Current HIV/AIDS reports 8:172-180. DOI: 10.1007/s11904-011-0088-2.

Ferreira-Borges C., Parry CDH., Babor TF. 2017. Harmful Use of Alcohol: A Shadow over SubSaharan Africa in Need of Workable Solutions. International Journal of Environmental Research and Public Health 14. DOI: 10.3390/ijerph14040346. 29:299-305.

Ishak WW., Bagot K., Thomas S., Magakian N., Bedwani D., Larson D., Brownstein A., Zaky C. 2012. Quality of Life in Patients Suffering from Insomnia. Innovations in Clinical Neuroscience 9:13-26.

Jafari Roodbandi A., Choobineh A., Daneshvar S. 2015. Relationship between circadian rhythm amplitude and stability with sleep quality and sleepiness among shift nurses and health 
care workers. International journal of occupational safety and ergonomics: JOSE 21:312-317. DOI: 10.1080/10803548.2015.1081770.

361

362

363

364

365

366

367

368

369

370

371

372

373

374

375

376

377

378

379

Johansson P., Arestedt K., Alehagen U., Svanborg E., Dahlström U., Broström A. 2010. Sleep disordered breathing, insomnia, and health related quality of life -- a comparison between age and gender matched elderly with heart failure or without cardiovascular disease. European Journal of Cardiovascular Nursing: Journal of the Working Group on Cardiovascular Nursing of the European Society of Cardiology 9:108-117. DOI: 10.1016/j.ejcnurse.2009.11.005.

Kang V., Shao J., Zhang K., Mulvey M., Ming X., Wagner GC. 2012. Sleep Deficiency and Sleep Health Problems in Chinese Adolescents. Clinical Medicine Insights. Pediatrics 6:11-17. DOI: 10.4137/CMPed.S8407.

Kenney SR., Paves AP., Grimaldi EM., LaBrie JW. 2014. Sleep Quality and Alcohol Risk in College Students: Examining the Moderating Effects of Drinking Motives. Journal of American college health: J of ACH 62:301-308. DOI: 10.1080/07448481.2014.897953.

Krishnan V., Dixon-Williams S., Thornton JD. 2014. Where There Is Smoke...There Is Sleep Apnea. Chest 146:1673-1680. DOI: 10.1378/chest.14-0772.

Mahfoud Y., Talih F., Streem D., Budur K. 2009. Sleep Disorders in Substance Abusers. Psychiatry (Edgmont) 6:38-42.

Martinez P., Røislien J., Naidoo N., Clausen T. 2011. Alcohol abstinence and drinking among African women: data from the World Health Surveys. BMC Public Health 11:160. DOI: 10.1186/1471-2458-11-160. 
380 Moloney ME., Konrad TR., Zimmer CR. 2011. The Medicalization of Sleeplessness: A Public

381 Health Concern. American Journal of Public Health 101:1429-1433. DOI:

382 10.2105/AJPH.2010.300014.

383

384

385

386

387

388

389

390

391

392

393

394

395

396

397

398

399

400

401

402

O’Connell R., Chishinga N., Kinyanda E., Patel V., Ayles H., Weiss HA., Seedat S. 2013. Prevalence and Correlates of Alcohol Dependence Disorder among TB and HIV Infected Patients in Zambia. PLoS ONE 8. DOI: 10.1371/journal.pone.0074406.

Oluwole OSA. 2010. Sleep habits in Nigerian undergraduates. Acta Neurologica Scandinavica 121:1-6. DOI: 10.1111/j.1600-0404.2009.01171.x.

World Health Organization. Report on the WHO Regional Technical Consultation on a Global Strategy to Reduce Harmful Use of Alcohol. World Health Organization, Regional Office for Africa; Brazzaville, Congo: 2009.

Peter ID., Adamu H., Asani MO., Aliyu I., Sabo UA., Umar UI. 2017. Sleep Pattern and Sleep Hygiene Practices among Nigerian Schooling Adolescents. Indian Journal of Psychological Medicine 39:407-412. DOI: 10.4103/0253-7176.211743.

Popovici I., French MT. 2013. Binge Drinking and Sleep Problems among Young Adults. Drug and alcohol dependence 132:207-215. DOI: 10.1016/j.drugalcdep.2013.02.001.

Pot GK. 2017. Sleep and dietary habits in the urban environment: the role of chrono-nutrition. Proceedings of the Nutrition Society:1-10. DOI: 10.1017/S0029665117003974.

Rabiee R., Agardh E., Coates MM., Allebeck P., Danielsson A. Alcohol-attributed disease burden and alcohol policies in the BRICS-countries during the years 1990-2013. Journal of Global Health 7. DOI: 10.7189/jogh.07.010404.

Rachdaoui N., Sarkar DK. 2013. Effects of Alcohol on the Endocrine System. Endocrinology and metabolism clinics of North America 42:593-615. DOI: 10.1016/j.ecl.2013.05.008. 
403 Rachdaoui N., Sarkar DK. 2017. Pathophysiology of the Effects of Alcohol Abuse on the 404 Endocrine System. Alcohol Research : Current Reviews 38:255-276.

405

406

407

408

409

410

411

412

413

414

415

416

417

418

419

420

421

422

423

424

425

Roehrs T., Roth T. 2001. Sleep, sleepiness, and alcohol use. Alcohol Research \& Health: The Journal of the National Institute on Alcohol Abuse and Alcoholism 25:101-109.

van Schrojenstein Lantman M., Mackus M., Roth T., Verster JC. 2017. Total sleep time, alcohol consumption, and the duration and severity of alcohol hangover. Nature and Science of Sleep 9:181-186. DOI: 10.2147/NSS.S136467.

Shah N., Bang A., Bhagat A. 2010. Indian research on sleep disorders. Indian Journal of Psychiatry 52:S255-S259. DOI: 10.4103/0019-5545.69242.

Sharma MP., Andrade C. 2012. Behavioral interventions for insomnia: Theory and practice. Indian Journal of Psychiatry 54:359-366. DOI: 10.4103/0019-5545.104825.

Shield KD., Gmel G., Patra J., Rehm J. 2012. Global burden of injuries attributable to alcohol consumption in 2004: a novel way of calculating the burden of injuries attributable to alcohol consumption. Population Health Metrics 10:9. DOI: 10.1186/1478-7954-10-9.

Singleton RA., Wolfson AR. 2009. Alcohol consumption, sleep, and academic performance among college students. Journal of Studies on Alcohol and Drugs 70:355-363.

Soares CN. 2005. Insomnia in women: an overlooked epidemic? Archives of Women's Mental Health 8:205-213. DOI: 10.1007/s00737-005-0100-1.

Stein MD., Friedmann PD. 2005. Disturbed Sleep and Its Relationship to Alcohol Use. Substance abuse : official publication of the Association for Medical Education and Research in Substance Abuse 26:1-13.

Stranges S., Tigbe W., Gómez-Olivé FX., Thorogood M., Kandala N-B. 2012. Sleep Problems: An Emerging Global Epidemic? Findings From the INDEPTH WHO-SAGE Study 
426

427

428

429

430

431

432

433

434

435

436

437

438

439

440

Among More Than 40,000 Older Adults From 8 Countries Across Africa and Asia. Sleep 35:1173-1181. DOI: 10.5665/sleep.2012.

Tai Hing Lam, Chim D. 2010. Controlling Alcohol-Related Global Health Problems. Asia Pacific Journal of Public Health 22:203S-208S. DOI: 10.1177/1010539510373013.

Thakkar MM., Sharma R., Sahota P. 2015. Alcohol disrupts sleep homeostasis. Alcohol (Fayetteville, N.Y.) 49:299-310. DOI: 10.1016/j.alcohol.2014.07.019.

Tian G., Liu F. 2011. Is the Demand for Alcoholic Beverages in Developing Countries Sensitive to Price? Evidence from China. International Journal of Environmental Research and Public Health 8:2124-2131. DOI: 10.3390/ijerph8062124.

Watson NF., Badr MS., Belenky G., Bliwise DL., Buxton OM., Buysse D., Dinges DF., Gangwisch J., Grandner MA., Kushida C., Malhotra RK., Martin JL., Patel SR., Quan SF., Tasali E. 2015. Recommended Amount of Sleep for a Healthy Adult: A Joint Consensus Statement of the American Academy of Sleep Medicine and Sleep Research Society. Sleep 38:843-844. DOI: 10.5665/sleep.4716. 


\section{Table 1 (on next page)}

Sample characteristics. GDHS 2008. 
1

Table 1: Sample characteristics. GDHS 2008.

\begin{tabular}{|c|c|c|}
\hline & $\mathrm{N}=9,453$ & $\%$ \\
\hline \multicolumn{3}{|l|}{ Age } \\
\hline $15-19$ & 1974 & 20.9 \\
\hline $20-24$ & 1571 & 16.6 \\
\hline $25-29$ & 1422 & 15.0 \\
\hline $30-34$ & 1153 & 12.2 \\
\hline $35-39$ & 1145 & 12.1 \\
\hline $40-44$ & 872 & 9.2 \\
\hline 45 or above & 1316 & 13.9 \\
\hline \multicolumn{3}{|l|}{ Sex } \\
\hline Male & 4546 & 48.1 \\
\hline Female & 4907 & 51.9 \\
\hline \multicolumn{3}{|l|}{ Residency } \\
\hline Urban & 4066 & 43.0 \\
\hline Rural & 5387 & 57.0 \\
\hline \multicolumn{3}{|l|}{ Religion } \\
\hline Christian & 6714 & 71.0 \\
\hline Non-Christian & 2739 & 29.0 \\
\hline \multicolumn{3}{|l|}{ Ethnicity } \\
\hline Akan & 3962 & 41.9 \\
\hline Ewe & 1288 & 13.6 \\
\hline Mole-Dagbani & 2158 & 22.8 \\
\hline Other & 2045 & 21.6 \\
\hline \multicolumn{3}{|l|}{ Education } \\
\hline No education & 2021 & 21.4 \\
\hline primary & 1723 & 18.2 \\
\hline Secondary & 5155 & 54.5 \\
\hline Higher & 554 & 5.9 \\
\hline
\end{tabular}




$\begin{array}{lcc}\begin{array}{l}\text { No. of household } \\ \text { member }\end{array} & & \\ 4 & 4426 & 46.8 \\ 6 & 2608 & 27.6 \\ 8 & 1446 & 15.3 \\ 8+ & 973 & 10.3 \\ \text { Has electricity } & & \\ \text { No } & 4215 & 44.6 \\ \text { Yes } & 5235 & 55.4 \\ \text { Rooms used for } & & \\ \text { sleeping } & & \\ 2 & 6878 & 72.8 \\ 4 & 1850 & 19.6 \\ 6 & 390 & 4.1 \\ 6+ & 335 & 3.5\end{array}$

\section{Has Bed}

No 1481

15.7

Yes

7972

84.3

Has bed net

No

Yes

5260

55.6

Wealth index

Poorest

Poorer

1785

18.9

Middle

1628

17.2

Richer

1979

20.9

Richest

1894

20.0

Working

No

Yes

7352

77.8

Smokes cigar 


$\begin{array}{lcc}\text { No } & 9059 & 95.8 \\ \text { Yes } & 394 & 4.2 \\ \text { Drinks alcohol } & & \\ \text { No } & 6809 & 72.0 \\ \text { Yes } & 2644 & 27.9\end{array}$

3

4

5 


\section{Table 2 (on next page)}

Sleeping hours across the explanatory variables. GDHS 2008. 
Table 2: Sleeping hours across the explanatory variables. GDHS 2008.

\begin{tabular}{|c|c|c|c|c|}
\hline \multirow[t]{2}{*}{ Variables } & \multicolumn{3}{|c|}{ Sleeping hours } & \multirow{2}{*}{$\begin{array}{c}p- \\
\text { value }\end{array}$} \\
\hline & $\begin{array}{c}1-3 \\
1.5 \%(1.2-2.0)\end{array}$ & $\begin{array}{c}4-6 \\
14.1 \%(12-16.5)\end{array}$ & $\begin{array}{c}>7 \\
84.4 \%(82.1-86.4)\end{array}$ & \\
\hline \multicolumn{5}{|l|}{ Age } \\
\hline $15-19$ & $19.5(13.5-27.5)$ & $12.7(10.1-15.7)$ & $21.7(20.6-23.0)$ & $<0.001$ \\
\hline $20-24$ & $11.8(6.7-19.8)$ & $14.1(12.0-16.4)$ & $17.2(15.9-18.5)$ & \\
\hline $25-29$ & $18.0(12.0-26.1)$ & $14.2(12.0-16.7)$ & $15.5(14.6-16.5)$ & \\
\hline $30-34$ & $11.9(7.4-18.6)$ & $15.8(13.3-18.7)$ & $11.8(11.0-12.7)$ & \\
\hline $35-39$ & $12.3(7.3-19.8)$ & $15.2(13.4-17.3)$ & $11.8(11.0-12.6)$ & \\
\hline $40-44$ & $7.5(4.0-13.8)$ & $10.6(8.9-12.6)$ & $8.9(8.2-9.6)$ & \\
\hline $45-49$ & $19.0(12.7-27.5)$ & $17.4(15.4-19.6)$ & $13.0(11.5-14.8)$ & \\
\hline \multicolumn{5}{|l|}{ Sex } \\
\hline Male & $45.8(29.3-63.2)$ & $57.9(41.7-72.5)$ & $46.5(33.7-59.7)$ & $<0.001$ \\
\hline Female & $54.2(36.8-70.7)$ & $42.1(27.5-58.3)$ & $53.5(40.3-66.3)$ & \\
\hline \multicolumn{5}{|l|}{ Residency } \\
\hline Urban & $41.6(27.3-57.4)$ & $54.3(37.0-70.7)$ & $46.5(35.3-58.1)$ & $<0.001$ \\
\hline Rural & $58.4(42.6-72.7)$ & $45.7(29.3-63.0)$ & $53.5(41.9-64.7)$ & \\
\hline \multicolumn{5}{|l|}{ Religion } \\
\hline Christian & $55.7(44.4-66.5)$ & $24.6(21.1-28.4)$ & $24.6(20.0-29.9)$ & $<0.001$ \\
\hline Non-Christian & $44.3(33.5-55.6)$ & $75.4(71.6-78.9)$ & $75.4(70.1-80.0)$ & \\
\hline \multicolumn{5}{|l|}{ Ethnicity } \\
\hline Akan & $38.0(26.6-50.9)$ & $48.1(40.3-56.1)$ & $49.5(42.6-56.4)$ & $<0.001$ \\
\hline Ewe & $7.8(4.0-14.6)$ & $18.0(12.7-24.9)$ & $13.2(9.3-18.3)$ & \\
\hline Mole-Dagbani & $35.8(25.3-47.9)$ & $11.1(8.3-14.7)$ & $16.9(12.4-22.6)$ & \\
\hline Other & $18.4(10.6-30.0)$ & $22.8(19.1-26.9)$ & $20.4(16.8-24.5)$ & \\
\hline \multicolumn{5}{|l|}{ Education } \\
\hline No education & $30.9(22.2-41.3)$ & $17.4(13.1-22.7)$ & $17.5(13.6-22.2)$ & $<0.001$ \\
\hline
\end{tabular}




\begin{tabular}{|c|c|c|c|c|}
\hline primary & $18.0(12.5-25.1)$ & $14.6(11.5-18.3)$ & $17.9(16.0-19.9)$ & \\
\hline Secondary & $45.2(34.5-56.3)$ & $57.3(52.9-61.6)$ & $59.0(54.3-63.5)$ & \\
\hline Higher & $5.9(2.9-11.6)$ & $10.7(6.4-17.3)$ & $5.6(4.5-7.1)$ & \\
\hline $\begin{array}{l}\text { No. of house } \\
\text { member }\end{array}$ & nold & & & \\
\hline 4 & $40.9(32.9-49.5)$ & $53.9(48.7-59.0)$ & $48.9(45.5-52.4)$ & $<0.001$ \\
\hline 6 & $34.4(25.3-44.6)$ & $28.1(24.7-31.7)$ & $27.4(25.7-29.1)$ & \\
\hline 8 & $9.9(6.0-16.0)$ & $10.9(8.8-13.4)$ & $14.9(13.3-16.7)$ & \\
\hline $8+$ & $14.8(8.5-24.7)$ & $7.1(5.6-9.0)$ & $8.8(7.0-10.9)$ & \\
\hline Has electricity & & & & \\
\hline No & $53.4(39.6-64.7)$ & $33.0(22.9-40.9)$ & $39.5(32.9-46.5)$ & $<0.001$ \\
\hline Yes & $46.6(34.1-59.4)$ & $67.0(57.0-75.7)$ & $59.5(52.3-66.0)$ & \\
\hline $\begin{array}{l}\text { Rooms used } \\
\text { sleeping }\end{array}$ & for & & & \\
\hline 2 & $61.5(49.7-72.2)$ & $77.0(73.1-80.5)$ & $75.9(72.4-79.1)$ & $<0.001$ \\
\hline 4 & $20.2(12.4-31.1)$ & $17.2(14.1-20.8)$ & $17.7(15.5-20.1)$ & \\
\hline 6 & $8.8(5.0-14.9)$ & $2.8(2.0-3.8)$ & $3.4(2.7-4.3)$ & \\
\hline $6+$ & $9.5(5.1-17.0)$ & $3.0(2.1-4.3)$ & $3.0(2.3-3.9)$ & \\
\hline
\end{tabular}

\section{Has Bed}

No

$12.8(6.8-22.8)$

$8.9(6.5-12.2)$

$12.7(9.6-16.4)$

$<0.001$

Yes

$87.2(77.2-93.2)$

$91.1(87.8-93.5)$

$87.3(83.6-90.4)$

\section{Has bed net}

No

$45.8(36.0-55.9) \quad 48.5(43.7-53.3) \quad 47.2(43.3-51.1) \quad 0.372$

Yes

$54.2(44.1-64.0) \quad 51.5(46.7-56.3) \quad 52.8(48.9-56.7)$

\section{Wealth index}

$\begin{array}{lcccc}\text { Poorest } & 31.6(20.1-45.9) & 13.0(8.5-19.3) & 17.1(12.1-23.6) & <0.001 \\ \text { Poorer } & 21.9(14.3-32.1) & 15.1(10.3-21.7) & 18.5(15.3-22.3) & \\ \text { Middle } & 13.6(8.4-21.2) & 17.7(12.9-23.8) & 18.8(16.0-22.0) & \\ \text { Richer } & 19.3(11.8-30.0) & 24.0(20.7-27.7) & 23.1(20.0-26.6) \\ \text { Richest } & 13.6(7.9-22.4) & 30.2(19.3-43.8) & 22.5(16.4-30.0) \\ \text { Working } & & & \end{array}$




\begin{tabular}{lcccc} 
No & $25.3(18.2-33.9)$ & $12.6(10.9-14.6)$ & $23.9(22.3-25.6)$ & $<0.001$ \\
Yes & $74.7(66.1-81.8)$ & $87.4(85.4-89.1)$ & $76.1(74.4-77.7)$ & \\
Smokes cigar & & & & \\
No & $96.9(91.8-98.9)$ & $95.9(93.8-97.3)$ & $96.4(95.0-97.5)$ & $<0.001$ \\
Yes & $3.1(1.1-8.2)$ & $4.1(2.7-6.2)$ & $3.6(2.5-5.0)$ & \\
Drinks alcohol & & & & \\
No & $78.8(69.8-85.6)$ & $66.5(61.7-70.9)$ & $74.2(70.5-77.4)$ & 0.124 \\
Yes & $21.2(14.4-30.2)$ & $33.5(29.1-38.3)$ & $25.8(22.5-29.4)$ & \\
\hline
\end{tabular}

3

4

5 


\section{Table 3 (on next page)}

Odds ratios of sleeping 4-6 hours and 1-3 hours among drinkers. GDHS 2008.

Regression analysis 
Table 3: Odds ratios of sleeping 4-6 hours and 1-3 hours among drinkers. GDHS 2008.

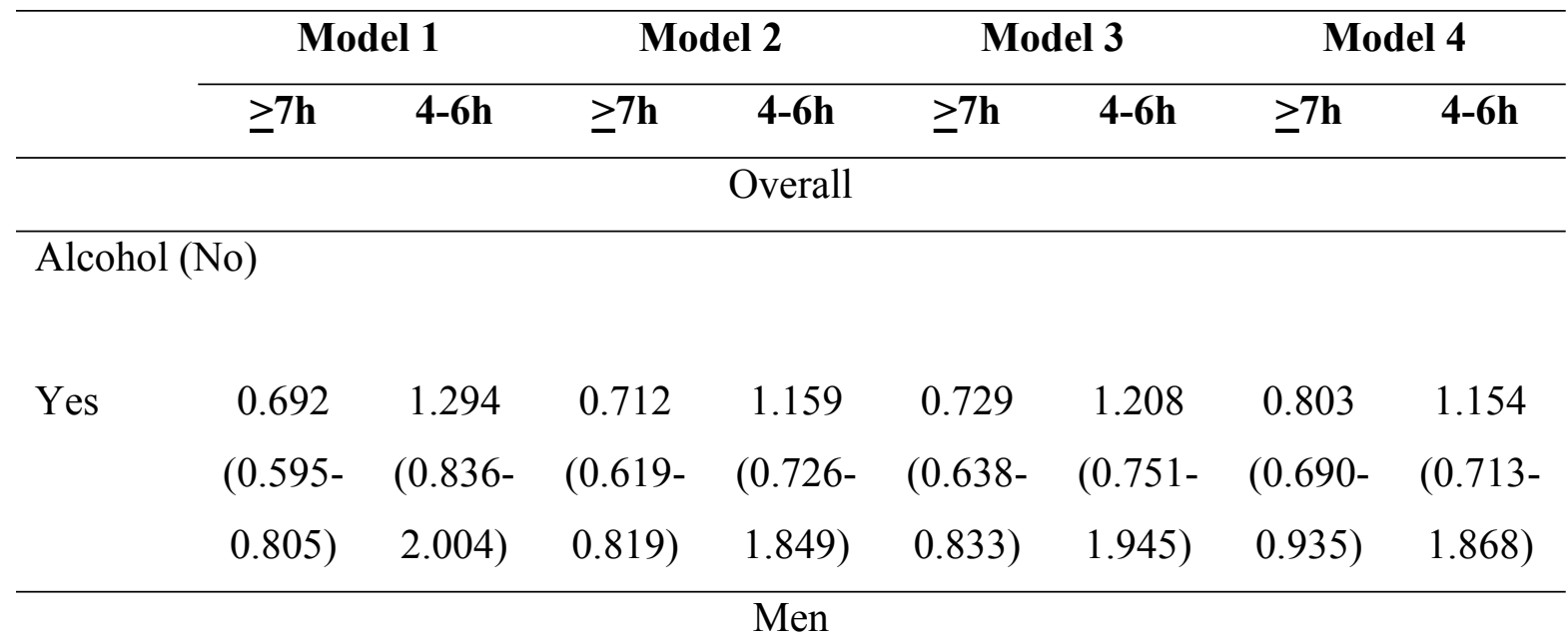

Alcohol (No)

$\begin{array}{lllllllll}\text { Yes } & 0.820 & 0.983 & 0.847 & 0.993 & 0.846 & 0.994 & 0.867 & 0.986\end{array}$ $\begin{array}{llllllll}(0.679- & (0.554- & (0.725- & (0.543- & (0.727- & (0.545- & (0.740- & (0.529-\end{array}$

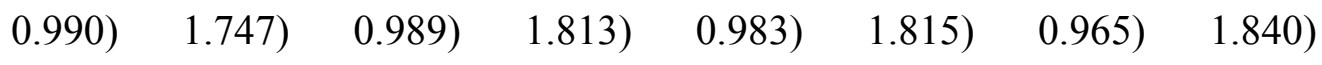

Women

Alcohol (No)

$\begin{array}{lllllllll}\text { Yes } & 0.664 & 2.236 & 0.640 & 2.113 & 0.653 & 2.201 & 0.657 & 2.170\end{array}$ $(0.514-\quad(0.867-\quad(0.496-\quad(0.816-\quad(0.507-\quad(0.855-\quad) \quad(0.509-\quad) \quad(0.840-$

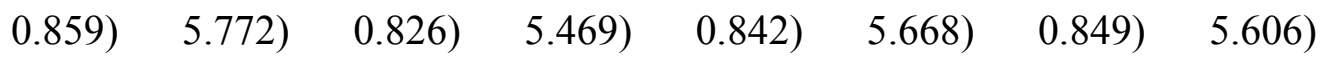

4 N.B. Reference category= 1-3 hours. Model 1=Age, sex; Model 2=Model 1, residence, religion, 5 ethnicity; Model 3= Model 2; education, wealth status, employment; Model 4= Model 3, No. of 6 household members, has electricity, no. of rooms used for sleeping, has bed, smoking. 